\title{
Rapid techniques for DNA extraction from routinely processed archival tissue for use in PCR
}

\author{
R Sepp, I Szabó, H Uda, H Sakamoto
}

\begin{abstract}
Aims-To evaluate the ability of four rapid DNA extraction methods to provide DNA for the polymerase chain reaction (PCR) from routinely fixed, paraffin wax embedded archival tissues.

Methods-Eighteen blocks of various tissues, 18 blocks of cervical cancer specimens, and nine blocks of $B$ cell lymphomas were investigated. Both normal and biopsy specimen sized tissues were studied. DNA was extracted using four methods: boiling for 20 minutes in distilled water; boiling for 20 minutes in 5\% Chelex-100 resin solution; 3-hour proteinase $K$ digestion; and 3-hour proteinase $\mathrm{K}$ digestion, followed by boiling in $5 \%$ Chelex-100. Different exons of the p53 gene, human papillomavirus type 16 (HPV 16) sequence, and immunoglobulin heavy chain (IgH) gene rearrangement were amplified from the extracts.
\end{abstract}

Results-The Chelex boiling, proteinase $K$ digestion, and proteinase $K$ digestionChelex boiling methods produced DNA suitable for amplification in all of the 45 samples. Boiling in water yielded insufficient template for the PCR in three of the 45 cases $(7 \%)$, and in six of 42 positive cases $(14 \%)$ much fainter bands were observed, mostly when the processed material was either biopsy specimen sized or a B cell lymphoma sample. Fragments of the p53 gene were successfully amplified up to 408 base pairs in water boiled extracts, up to 647 in Chelex boiled preparates, and up to 984 in proteinase $K$ digested and proteinase $K$ digested-Chelex boiled samples, although with decreased sensitivity in the last case. All of the templates were reusable after 3 months of storage at $-20^{\circ} \mathrm{C}$.

Conclusions-Chelex boiling, proteinase $K$ digestion, and proteinase $K$ digestion followed by Chelex boiling produce suitable templates for the PCR from a large variety of paraffin wax embedded tissues. As the simple 20 minute boiling method in $5 \%$ Chelex-100 solution requires minimal manipulation and time, it could be useful, especially in the routine processing of large amounts of material.

( Clin Pathol 1994;47:318-323)

The polymerase chain reaction (PCR) is a method for the in vitro amplification of specific nucleic acid sequences. ${ }^{1}$ The technology provides a powerful means for the rapid detection of infections, particularly those by viral pathogens, ${ }^{2-5}$ of gene rearrangements in lymphoproliferative disorders, ${ }^{67}$ and of inherited diseases. ${ }^{8}$ Furthermore, the technique can serve as an initial step for PCR based investigations.

An attractive feature of PCR is that, unlike other molecular biological procedures, high molecular weight DNA is not required for successful amplification. As minute quantities of degraded DNA can also serve as the substrate for the reaction, the method is ideally suited to a template extracted from formalin fixed, paraffin wax embedded archival material. The combined advantages of exquisite sensitivity and the ability to use routinely processed materials allow large scale, retrospective studies to be carried out.

The most widespread protocols for DNA extraction from formalin fixed, paraffin embedded tissues utilise shorter or longer proteolytic treatment-ranging from three hours to several days - with or without additional organic solvent purification and ethanol precipitation..$^{9-13}$ An alternative procedure for tissue processing for PCR involves lysing cells by boiling in distilled water ${ }^{314}{ }^{15}$ or in a solution containing a chelating resin. ${ }^{4516}$ Other methods such as sodium dodecyl sulphate (SDS) incubation ${ }^{12}{ }^{15}$ or sonication ${ }^{17}$ have also been described.

For the large scale, routine processing of archival material, DNA extraction should be simple and rapid, with no influence on the success of the PCR. Moreover, as few steps as possible should be involved to minimise the possibility of contamination. The laborious and hazardous phenol-chloroform extraction should be particularly avoided.

Previous reports have focused mainly on quantitative issues comparing DNA obtained from fresh or fixed tissues, ${ }^{51217}$ and have examined applicable methods separately ${ }^{14}{ }^{16}$ or have compared them in the amplification of only a few similar target sequences. ${ }^{412}$

We performed a qualitative study, comparing several reported rapid DNA extraction procedures which take less than 4 hours. The ability of these methods to provide DNA suitable for the PCR was investigated. For a more precise comparison, various sets of primers were chosen to amplify a single copy human gene, a viral sequence, and a rearranged immunoglobulin gene. Several practical aspects of the PCR were also examined, taking into consideration the size of the 
processed tissue, previous dewaxing, target sequence length, and the reuse of extracts.

\section{Methods}

Blocks of formalin fixed, paraffin wax embedded archival tissues were selected from the files of the Department of Pathology, Kagawa Medical School, Japan. Normal sized (average surface dimensions $16 \times 18 \mathrm{~mm}$ ) and biopsy specimen sized (average surface dimensions $1.7 \times 2 \mathrm{~mm}$ ) tissue samples were collected and divided into the following groups:

(1) Twelve blocks of normal sized and six blocks of biopsy specimen sized material, randomly chosen from various tissues; they represented neoplastic, inflammatory, or hyperplastic processes of the skin, soft tissue, tonsils, oesophagus, duodenum, colon, pancreas, lung, kidney, urinary bladder, meninges, ovary, cervix, normal placenta, and endometrium

(2) twelve blocks of normal sized cervical cancer samples and an additional six blocks of cervical biopsy specimens (diagnosed as cancer or severe dysplasia), known to harbour human papilloma virus type 16 (HPV 16) DNA by the authors' previous PCR assays

(3) six blocks of normal sized non-Hodgkin's B cell lymphoma samples (B-NHL) and an additional three blocks of B-NHL biopsy specimens, known to have detectable immunoglobulin heavy chain ( $\operatorname{IgH})$ gene rearrangement according to the authors' previous PCR results.

The material was processed between 1988 and 1993. Fixation was in neutral formalin, and the fixation time varied from 24 to 48 hours. Processing was done by standard methods: dehydration in graded alcohols; clearing in xylene; and embedding in paraffin wax.

\section{DNA EXTRACTION}

From normal sized tissues a single $5 \mu \mathrm{m}$ section (average collected volume $1.44 \mathrm{~mm}^{3}$ ) and from biopsy specimen sized tissues a single $10 \mu \mathrm{m}$ section (average collected volume $0.034 \mathrm{~mm}^{3}$ ) were cut and processed according to the following four methods (Methods A-D).

\section{Method A}

The section was resuspended in $100 \mu \mathrm{l}$ distilled water ( $50 \mu \mathrm{l}$ for biopsy specimen sized material), with or without pretreatment, and was boiled for 20 minutes (modified from the method of Lench et $a^{15}$ ). Pretreatment, if performed, consisted of dewaxing by two washes in xylene at $60^{\circ} \mathrm{C}$ for 20 minutes, rehydration in absolute ethanol, and desiccation.

\section{Method B}

This was similar to Method A, but the section was resuspended in 5\% Chelex-100 resin solution (Bio Rad Laboratories, Hercules, California, USA) and was boiled for $20 \mathrm{~min}$ utes. ${ }^{18}$

\section{Method C}

After dewaxing and rehydration, the tissue section was resuspended in $100 \mu \mathrm{l}(50 \mu \mathrm{l}$ for biopsy specimen sized material) of digestion buffer ( $50 \mathrm{mM} \mathrm{KCl}, 1.5 \mathrm{mM} \mathrm{MgCl}, 10 \mathrm{mM}$ TRIS-HCl, $0.5 \%$ TWEEN $20, \mathrm{pH} 9$ at $25^{\circ} \mathrm{C}$ ) containing $200 \mu \mathrm{g} / \mathrm{ml}$ proteinase $\mathrm{K}$ (Merck, Darmstadt, Germany) and was incubated at $55^{\circ} \mathrm{C}$ for 3 hours (or at $37^{\circ} \mathrm{C}$ overnight).$^{19}$ The proteinase $\mathrm{K}$ was inactivated by boiling for eight minutes.

\section{Method D}

This was similar to Method C, but after digestion Chelex-100 was added to a final concentration of $5 \%$, and the mixture was boiled for eight minutes (modified from the method of Gill et $a l^{20}$ ).

After boiling, all the tubes were chilled on ice, and were centrifuged for five minutes at $18000 \times g$. An aliquot of $5 \mu \mathrm{l}$ of the supernatant (10 $\mu$ l for biopsy specimen sized tissue) was used as the template.

\section{OLIGONUCLEOTIDE PRIMERS}

The sequences, target regions, and other characteristics of the primers are shown in table 1. Three types of primer set were used: one for different exons of the p53 gene as a normal single copy human gene, on the randomly chosen tissues; a second type for the open reading frame region E6 of HPV 16 on cervical samples; and a third type for IgH gene rearrangement on $\mathrm{B}$ cell lymphomas. Oligonucleotides were synthesised on a

Table 1 Oligonucleotide primers used in the study

\begin{tabular}{|c|c|c|c|c|}
\hline Primer & Sequence $\left(5^{\prime}-3^{\prime}\right)$ & Target region & $\begin{array}{l}\text { Size of PCR } \\
\text { product } \\
\text { (base pairs) }\end{array}$ & Source \\
\hline \multirow{11}{*}{$\begin{array}{l}\text { E81 } \\
\text { E82 } \\
\text { E71 } \\
\text { E72 } \\
\text { E61 } \\
\text { E62 } \\
\text { E51 } \\
\text { E52 } \\
\text { E41 } \\
\text { E42 } \\
\text { H1 } \\
\text { H2 } \\
\text { Fr3A } \\
\text { LJH } \\
\text { VLJH }\end{array}$} & CCTATCCTGAGTAGTGGTAATCTAC & p53 gene, exon 8 & \multirow[t]{2}{*}{166} & \multirow[t]{8}{*}{ Miller et al ${ }^{21}$} \\
\hline & CTCCTAGGTTGGCTCTGACTGT & p53 gene, exon 7 & & \\
\hline & CAAGTGGCTCCTGACCTGGA & \multirow{3}{*}{ p53 gene, exon 6} & 131 & \\
\hline & CACTGATTGCTCTTAGGTCTGGC & & \multirow[t]{2}{*}{144} & \\
\hline & AGTTGCAAACCAGACCTCAGGCG & & & \\
\hline & TTCCTCTTCCTGCAGTAC & p53 gene, exon 5 & \multirow[t]{2}{*}{214} & \\
\hline & GCCCCAGCTGCTCACCATCG & & & \\
\hline & $\begin{array}{l}\text { AAAACCTACCAGGGCAGCTAC } \\
\text { CTCAGGGCAACTGACCGTG }\end{array}$ & p53 gene, exon 4 & 99 & \\
\hline & $\begin{array}{l}\text { ATTAGTGAGTATAGACATTA } \\
\text { GGCTTTGACAGTTAATACA }\end{array}$ & HPV 16, ORF E6 & 110 & Shibata $e t a l^{3}$ \\
\hline & $\begin{array}{l}\text { ACACGGC(C/T) (G/C) TGTATTACTGT } \\
\text { TGAGGAGACGGTGACC }\end{array}$ & $\begin{array}{l}\text { IgH gene, } \mathrm{V} \text { region } \\
\text { IgH gene, I region }\end{array}$ & $\underline{80}^{80-120}$ & Wan et $a l^{6}$ \\
\hline & GTGACCAGGGT(A/G/C/T)CCTTGGCCCCAG & & & \\
\hline
\end{tabular}


Cyclone Plus automated DNA synthesiser (Millipore, Bedford, Massachusetts, USA).

PCR

The PCR was carried out in a Perkin Elmer Cetus Thermal Cycler (Perkin-Elmer, Norwalk, Connecticut, USA). The reaction mixture (in $50 \mu \mathrm{l}$ or $25 \mu \mathrm{l}$ total volume) contained 10-20 pmol of primers, $1 \times$ PCR buffer $(50 \mathrm{mM} \mathrm{KCl}, 10 \mathrm{mM}$ TRIS- $\mathrm{HCl}$, $3 \mathrm{mM} \mathrm{MgCl}, \mathrm{pH} 9$ at $25^{\circ} \mathrm{C}$ ), $0.2 \mathrm{mM}$ each of dATP, dCTP, dGTP, and dTTP, 0.625$1.25 \mathrm{U}$ of Taq polymerase (Pharmacia Biotech, Milwaukee, Wisconsin, USA), and the template. The reaction mixture was overlaid with a drop of light mineral oil (Sigma, St Louis, Missouri, USA).

Each PCR cycle consisted of a denaturation step at $94^{\circ} \mathrm{C}$ for 30 seconds, primer annealing at $60^{\circ} \mathrm{C}\left(55^{\circ} \mathrm{C}\right.$ for $\mathrm{H} 1$ and $\mathrm{H} 2$ primers) for 30 seconds, and extension at $72^{\circ} \mathrm{C}$ for 1 minute. An initial denaturation step was performed at $94^{\circ} \mathrm{C}$ for 2 minutes, and in the final cycle the extension step was elongated to 5 minutes at $72^{\circ} \mathrm{C}$. Samples were amplified through 35 (for normal sized samples) or 40 cycles (biopsy specimen sized samples).

For biopsy specimen sized B cell lymphoma samples, seminested PCR was performed: a first round of 30 cycles with primers Fr3A and $\mathrm{LJH}$; and a second round of 35 cycles with Fr3A and VLJH, with $1 \mu \mathrm{l}$ of the product of the first round of the PCR as the template. ${ }^{6}$

In all runs positive and negative controls were included. The positive and negative controls were as follows: HPV 16 positive DNA (Genemed, San Francisco, California, USA) and DNA extracted from human $T$ cell lymphotrophic virus type I (HTLV-I) carrier cell line, respectively, for the HPV 16 PCR; high molecular weight DNA extracted from fresh frozen human lung and distilled water, respectively, for the p53 PCR; and DNA extracted from paraffin wax embedded $\mathrm{B}$ cell and $T$ cell lymphoma samples, respectively, for the IgH PCR.

Sterile materials were used throughout, with strict precautions to avoid contamination or product carryover. ${ }^{22}$ DNA extraction, the PCR, and electrophoresis were performed in separate laboratories.

Table $2 P C R$ results on different materials prepared by Methods $A-D$ (numbers shown are positive cases/total cases)

\begin{tabular}{lcccc}
\hline & \multicolumn{2}{l}{ Method } & & \\
\cline { 2 - 5 } Material & $A$ & $B$ & $C$ & $D$ \\
\hline Normal sized: & $12 / 12$ & $12 / 12$ & $12 / 12$ & $12 / 12$ \\
$\quad$ Various samples & $12 / 12$ & $12 / 12$ & $12 / 12$ & $12 / 12$ \\
Cervix samples & $5 \star / 6$ & $6 / 6$ & $6 / 6$ & $6 / 6$ \\
B cell lymphoma samples & & & & $6 / 6$ \\
Biopsy specimen sized: & $4 \dagger / 6$ & $6 / 6$ & $6 / 6$ & $6 / 6$ \\
$\quad$ Various samples & $6 / 6$ & $6 / 6$ & $6 / 6$ & $3 / 3$ \\
Cervix samples & $3 / 3$ & $3 / 3$ & $3 / 3$ & $45 / 45$ \\
B cell lymphoma samples & $42 \ddagger / 45$ & $45 / 45$ & $45 / 45$ & \\
Total & & & &
\end{tabular}

* Fainter bands in four cases

$\dagger$ Fainter bands in two cases

F Fainter bands in six cases

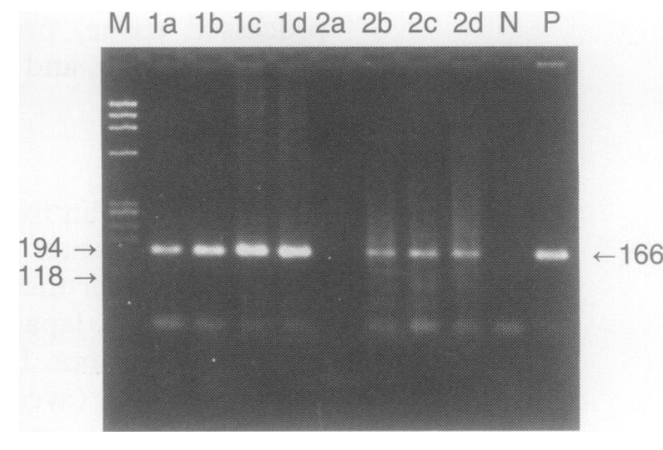

Figure $13 \%$ agarose electrophoresis gel of the PCR products, showing amplification of a 166 base pair fragment of exon 8 of the $p 53$ gene from DNA extracted from normal and biopsy specimen sized paraffin wax embedded tissue by different methods. M: $\varphi X 174$ DNA

Hae III digest. 1a-d: normal sized tissue sample of colonic adenocarcinoma processed by Methods $A$ (1a), $B(1 b)$, $C(1 c)$, and $D(1 d)$. 2a-d: biopsy specimen of duodenal polyp processed by Methods $A$ (2a), B (2b), $C(2 c)$, and $D(2 d) . N$ : negative control (distilled water instead of template). P: positive control (high molecular weight DNA as template, extracted from fresh frozen human lung). The sizes of the molecular weight marker and the specific band (in base pairs) are shown to the left and right, respectively.

\section{GEL ANALYSIS}

The quality of the template DNA was determined by running samples on $1 \%$ agarose gel (Wako Chemicals, Osaka, Japan) stained by ethidium bromide. Amplifications were analysed by electrophoresis of a $10 \mu \mathrm{l}$ aliquot through 3\% NuSieve GTG agarose (FMC Bioproducts, Rockland, Maine, USA), followed by ethidium bromide staining visualised by an ultraviolet light transilluminator. Bands of appropriate size were identified by comparison with DNA markers of known size.

\section{Results}

The overall results obtained by the PCR using the different primer sets are shown in table 2 .

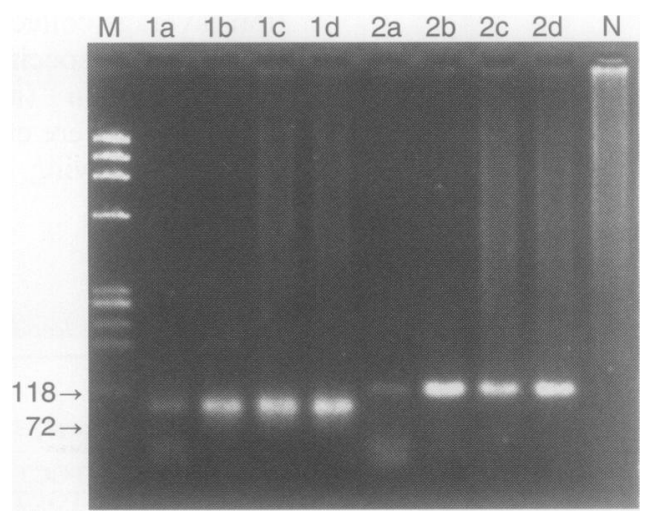

Figure $23 \%$ agarose electrophoresis gel of the PCR products, showing amplification of an 100-120 base pair fragment of a rearranged immunoglobulin heavy chain gene from DNA extracted from two normal sized $B$ chain gene from DNA extracted from two normal sized $B$
cell lymphoma samples by different methods. M: $\varphi X 174$ DNA Hae III digest. 1a-d: parotidal B cell lymphoma processed by Methods $A$ (1a), B (1b), $C$ (1c), and $D$ (1d). 2a-d: intestinal $B$ cell lymphoma processed by Methods $A(2 a), B(2 b), C(2 c)$, and $D(2 d)$. N: negative control (DNA extracted from a $T$ cell lymphoma sample as the template). The sizes of the molecular weight marker bands (in base pairs) are shown to the left. 


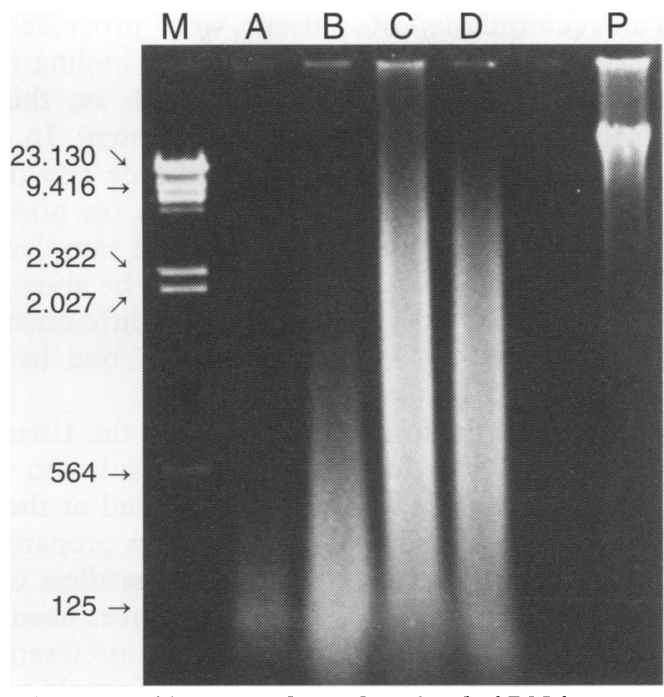

Figure $31 \%$ agarose electrophoresis gel of DNA extracted from a normal sized oesophageal carcinoma sample by different methods. M: $\lambda D N A$ Hind III digest; $(A)$ : boiled in distilled water (Method $A) ;(B):$ boiled in $5 \%$ Chelex solution (Method $B$ ); (C): proteinase $K$ digested (Method C); (D): proteinase $K$ digested and boiled in 5\% Chelex solution (Method D); P: positive control (high molecular weight DNA extracted from fresh frozen human lung). The sizes of the molecular weight marker bands (in base pairs) are shown to the left.

P53 GENE AMPLIFICATION IN VARIOUS

RANDOMLY CHOSEN TISSUES

A 166 base pair fragment of exon 8 or a 99 base pair fragment of exon 4 of the p53 gene was amplified. All of the templates prepared from normal sized tissues by different methods produced a single specific amplification band with the same intensity (fig 1, lanes 1ad). However, two of the biopsy specimen sized samples (33\% of the specimens) prepared by the water boiling method (Method A) failed to show the amplification, and in two other cases $(50 \%$ of the successful amplifications) the bands were much fainter. Biopsy samples prepared by Chelex boiling (Method

\section{1a 1b 1c 1d 1p 2a 2b 2c 2d 2p 3a 3b 3c 3d 3p}

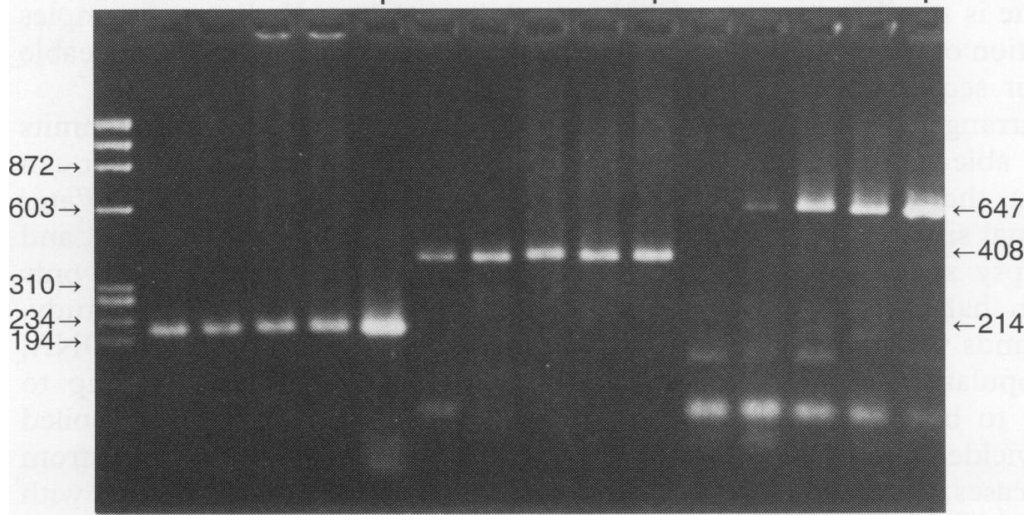

Figure $4 \quad 2 \cdot 5 \%$ agarose electrophoresis gel of PCR products showing amplification of exon 5 , exon 5-6, and exon 7-8 of the p53 gene from DNA extracted from a normal sized cervical cancer sample by different methods. $M: \varphi X 174$ DNA Hae III digest; 1 a-d: amplification of 214 base pair fragment from extracts prepared by Method $A(1 a), B$ (1b), $C$ (1c) and $D(1 d) ; 2 a-d$ : amplification of 408 base pair fragment from extracts prepared by Method $A(2 a), B(2 b), C(2 c)$ and $D(2 d) ; 3 a-d$ : amplification of 647 base pair fragment from extracts prepared by Method $A(3 a), B(3 b), C(3 c)$ and $D(3 d) ; 1 p$ 2p, 3p: positive controls (high molecular weight DNA as template, extracted from fresh frozen human lung). The sizes of the molecular weight marker and the specific bands (in frozen human lung). The sizes of the molecular weight
B), proteinase $\mathrm{K}$ digestion (Method $\mathrm{C}$ ) and proteinase $\mathrm{K}$ digestion-Chelex boiling (Method D) provided uniformly intense bands (fig 1, lanes 2a-d).

HPV 16 AMPLIFICATION IN CERVICAL SAMPLES A 110 base pair fragment of the open reading frame region E6 of HPV 16 was amplified. All of the samples prepared by the different methods from both normal and biopsy specimen sized tissues were successfully amplified (data not shown).

IMMUNOGLOBULIN GENE REARRANGEMENT AMPLIFICATION IN B CELL LYMPHOMA SAMPLES Depending on the given rearrangement of particular clones of B cell lymphomas, an 80-120 base pair fragment was amplified. One normal sized lymphoma specimen ( $17 \%$ of the normal sized B cell non-Hodgkin's lymphomas) prepared by the water boiling method failed to reveal amplification and in four other cases $(80 \%$ of the successful amplifications) much fainter bands were observed. DNA extracted by the other three methods produced intense bands of appropriate size in all cases (fig 2). The three biopsy specimens investigated by seminested PCR showed similar strong bands, regardless of the method used for extraction.

\section{ANALYSIS OF PREVIOUS DEWAXING}

To reduce further the number of steps involved in the extraction, the dewaxing and rehydration steps were omitted from the water boiling and Chelex boiling protocols. No differences were found in the successful amplifications using these extracts (data not shown).

ANALYSIS OF TEMPLATE QUALITY

The DNA extracted by the different methods was analysed on $1 \%$ agarose gel. There was evidence of extreme DNA degradation in templates prepared by water boiling (Method A), with the bulk between 100 and 200 base pairs. The DNA obtained by Chelex boiling (Method B) was better preserved, with a distribution in the 100-600 base pairs range. The proteinase $\mathrm{K}$ digestion methods (Methods C and D) produced DNA of increased molecular weight with a range from 100 to over 10000 base pairs, with the bulk between 100 and 4000 base pairs (fig 3 ).

ANALYSIS OF THE TARGET SEQUENCE LENGTH Combining forward and reverse primers, homologous to consecutive exons of the p53 gene, amplification products of gradually increasing length were able to be created. Primers E51 and E52 (flanking exon 5) amplify a target of 214 base pairs, while primers E51 and E62 (flanking exon 5 and 6), E71 and E82 (flanking exon 7 and 8) and E61 and E72 (flanking exon 6 and 7) amplify regions of 408, 647, and 983 base pairs, respectively. Two normal sized samples were analysed by this primer network.

Proteinase $\mathrm{K}$ digested and proteinase $\mathrm{K}$ digested-Chelex boiled templates were successfully amplified up to 983 base pairs (data 
not shown), although with an accumulation of non-specific products owing to uncompleted amplifications. Chelex boiled material showed a strong signal for 214 and 408 base pair targets, and still produced a weak band on the 647 base pair target. Water boiled material was successfully amplified on the 214 and 408 base pair targets only (fig 4 ).

\section{ANALYSIS OF THE REUSE OF TEMPLATES}

After three months of storage at $-20^{\circ} \mathrm{C}$, two samples from each group prepared by the four methods were successfully reamplified for their specific targets. However, 408 base pair targets produced weaker bands than freshly prepared samples, and amplification for the 647 base pair fragment was successful only in proteinase $K$ digested and proteinase $K$ digested-Chelex boiled samples (data not shown).

\section{Discussion}

Although formalin fixed tissues can also provide high molecular weight DNA, suitable for complex molecular biological investigations, ${ }^{911}$ the procedure requires lengthy digestion and purification steps, which would be difficult to perform on a large scale. The major attraction of the PCR, for research and diagnostic purposes in pathology, is its ability to work on poor quality DNA samples obtained by simple methods of extraction.

Four different techniques of rapid DNA extraction, from paraffin wax embedded tissues, were examined, from which PCR results can be obtained within 4-8 hours. DNA produced by the simplest water boiling method failed to be amplified for specific sequences in $7 \%$ of the total cases. In addition, in $14 \%$ of the positive samples the signal yielded was much weaker than in cases using other methods. Several investigators have also reported a variable degree of failure using this technique. ${ }^{41416}$ It seems likely that the cause of failure is the absence of a detectable amount of the target DNA. Theoretically, the amount of the released target DNA can be small if the size of the processed tissue is small (a biopsy specimen) or if only a portion of the processed material carries the target sequence (monoclonal B cells with a rearranged IgH gene). Indeed, the authors were able to amplify the p53 gene fragment from the water boiled extracts in all of the normal sized tissues but in only $66 \%$ of the biopsy specimen sized samples. Furthermore, in half of the latter successful cases fainter bands were observed. The presumed small population of monoclonal B cells also failed to be amplified in $17 \%$ of the samples, and yielded fainter bands in $80 \%$ of the positive cases, examined on normal sized B cell non-Hodgkin's lymphoma tissues. However, all of the biopsy specimen sized tissues were amplified successfully, probably due to the more sensitive seminested PCR, although it is also possible that the clonal population was more numerous in these cases. When $1 / 2,1 / 4,1 / 8$, and $1 / 16$ subdivisions of the same normal sized lymphoma tissue were processed, the samples prepared by the water boiling method produced clearly weaker bands on the $1 / 8$ and $1 / 16$ portions (data not shown). In contrast, the authors did not experience any difference when amplifying HPV 16 on normal or biopsy specimen sized cervical samples, where the target number seems to be above the limit that can cause discernible differences (cervical cancer cells may contain one to 50 copies of HPV per cell). ${ }^{23}$

Preparing the tissue samples by boiling in Chelex-100 solution produced enough DNA to be amplified at the same intensity as from those samples prepared by proteinase $K$ based methods, regardless of the tissue type, size, or target sequences used. Chelex-100 is a chelating resin that preferentially chelates polyvalent metal ions. Sample processing by Chelex has been successfully employed for a small number of cells, ${ }^{18}$ for forensic type materials, ${ }^{24}$ and for paraffin wax embedded tissues. ${ }^{4516}$ The effect of Chelex, which prevents the degradation of DNA, is thought to be due to chelating metal ions which may act as catalysts in the breakdown of DNA at high temperatures in low ionic strength solutions. ${ }^{18} 24$ Indeed, templates prepared by Chelex boiling in the present study were shown to be better preserved by electrophoretic examination than those prepared by the water boiling method (fig 3, lanes A and B). It is also possible that Chelex may bind other substances-blood derived products-which could inhibit the PCR itself. ${ }^{24}$

In the present study, 3 hour proteinase $\mathrm{K}$ digestion was also capable of yielding a sufficient amount of template DNA to amplify any of the targets in all of the cases. Although increasing the time of the digestion substantially improves the yield of DNA, ${ }^{12}$ for routine purposes this does not seem to be essential. However, to avoid phenol-chloroform extraction and to use the supernatant fluid directly, it is advisable to apply non-ionic detergents in the digestion buffer, instead of sodium dodecyl sulphate which was reported to inhibit Taq polymerase. ${ }^{1925}$ In this experiment, adding Chelex to the proteinase $\mathrm{K}$ digested samples (Method D) proved to have no noticeable influence on the sample quality.

These results also indicate several limits regarding the size of the products which can be amplified from various extracts. Water boiled samples are extremely degraded and were found to allow amplifications up to only 400 base pair fragments in the present study. With a better preservation of the target DNA, it was possible to amplify fragments up to about 650 base pairs from Chelex boiled material and up to about 1000 base pairs from proteinase $\mathrm{K}$ digested material, although with compromised specificity. Nevertheless, this amplification product size is unlikely to be used for diagnostic purposes.

Dewaxing seems to have no effect on the successful release of DNA from paraffin wax embedded tissues. No difference was found when tissues were boiled with or without previous deparaffinisation, which is in 
agreement with other observations. ${ }^{414}$ Although tissues were dewaxed before proteinase $\mathbf{K}$ digestion, other investigators have eliminated this step without any effect on the yield or quality of DNA obtained..$^{12}$

All extracts were reamplified for their relatively short (80-166 base pairs) specific targets, after storing them at $-20^{\circ} \mathrm{C}$ for three months. However, weakening in the product intensity was observed for the 408 base pair fragment, and failure to reamplify the 647 base pair fragment was noted from Chelex boiled samples. This decreased amplification ability was also reported in stored proteinase $\mathrm{K}$ digested samples, and is likely to be due to degradation or breaking of the DNA. ${ }^{13}$

In conclusion, the simplest water boiling method may fail to produce a sufficient quantity and quality of template from formalin fixed, paraffin wax embedded tissues, particularly when the starting material is small, the target molecules are expected to be of low copy number, or longer fragments are to be amplified. DNA prepared by Chelex boiling is of a quality which can be amplified as successfully, in all practical aspects, as that extracted by proteinase $\mathrm{K}$ digestion. As the procedure is simpler, requires less time and less manipulation-thus decreasing the possibility of contamination-it would be helpful for the large scale, routine treatment of paraffin wax embedded samples for the use of PCR.

R Sepp is an invited researcher from the Department of Pathology, A Szent-Györgyi University of Medicine, Szeged Pathology, A Szent-Györgyi University of Medicine, Szeged, Hungary. I Szabó is a scholar from the Department of Surgery, A Szent-Györgyi University of Medicine, Szeged, Hungary, and is supported by the Ministry of Education, Science and
Culture of Japan. The authors are indebted to Professor Culture of Japan. The authors are indebted to Professor Masazumi Maeda for providing p53 gene primers, and to Dr Chubun Sato for helpful discussions. They are also grateful to
Sumiko Tanaka for her help in preparation of the photographs and to Dr Naima Janjua for reviewing the manuscript.

1 Saiki RK, Gelfand DH, Stoffel S, et al. Primer-directed enzymatic amplification of DNA with a thermostable DNA polymerase. Science 1988;239:487-91.

2 Figueroa ME, Rasheed S. Molecular pathology and diagnosis of infectious diseases. Am $\mathscr{f}$ Clin Pathol 1991; 95(suppl 1):S8-21.

3 Shibata DK, Arnheim N, Martin WJ. Detection of human papilloma virus in paraffin-embedded tissue using the polymerase chain reaction. $\mathcal{F}$ Exp Med $1988 ; 167: 225-30$.

4 Kiene P, Milde-Langosch K, Runkel M, Shulz K, Löning $T$. A simple and rapid technique to process formalinfixed, paraffin-embedded tissues for the detection of viruses by the polymerase chain reaction. Virchows Arch (Pathol Anat) 1992;420:269-73.
5 Chen M-L, Shieh YSC, Shim K-S, Gerber MA. Comparative studies on the detection of hepatitis $B$ virus DNA in frozen and paraffin sections by the polymerase chain reaction. Mod Pathol 1991;4:555-8.

6 Wan JH, Trainor KJ, Brisco MJ, Morley AA. Monoclonality in B cell lymphoma detected in paraffin wax embedded sections using the polymerase chain reaction. embedded sections using the pol

7 Ramasamy I, Brisco M, Morley A. Improved PCR method for detecting monoclonal immunoglobulin heavy chain rearrangement in B cell neoplasms. $\mathcal{f}$ Clin Pathol 1992; 45:770-5.

8 Kogan SC, Doherty M, Gitschier J. An improved method for prenatal diagnosis of genetic diseases by analysis of amplified DNA sequences. $N$ Engl 7 Med 1987;317: 985-90.

9 Goelz SE, Hamilton SR, Vogelstein B. Purification of DNA from formaldehyde fixed and paraffin embedded human tissue. Biochem Biophys Res Commun 1985;130: 118-26.

10 Impraim CC, Saiki RK, Erlich HA, Teplitz RL. Analysis of DNA extracted from formalin-fixed, paraffin-embedded tissues by enzymatic amplification and hybridization with sequence-specific oligonucleotides. Biochem Biophys Res Commun 1987;142:710-16.

11 Dubeau L, Chandler LA, Gralow JR, Nichols PW, Jones PA. Southern blot analysis of DNA extracted from formalin-fixed pathology specimens. Cancer Res 1986;46: 2964-9.

12 Jackson DP, Lewis FA, Taylor GR, Boylston AW, Quirke P. Tissue extraction of DNA and RNA and analysis by the polymerase chain reaction. $f$ Clin Pathol 1990;43: the polym

13 Wright DK, Manos MM. Sample preparation from paraffin-embedded tissues. In: Innis MA, ed. $P C R$ protocols: a guide to methods and applications. San Diego: Academic Press, 1990: 153-6.

14 Coates PJ, d'Ardenne AJ, Khan G, Kangro HO, Slavin G. Simplified procedures for applying the polymerase chain reaction to routinely fixed paraffin wax sections. $f$ Clin Pathol 1991;44:115-18.

15 Lench N, Stainer P, Williamson R. Simple non-invasive method to obtain DNA for gene analysis. Lancet 1988; i: $1356-8$.

16 Stein A, Raoult D. A simple method for amplification of DNA from paraffin-embedded tissues. Nucleic Acid Res DNA from paraffin.

17 Heller MJ, Robinson RA, Burgart LJ, TenEyck CJ, Wilke WW. DNA extraction by sonication: a comparison of fresh, frozen, and paraffin-embedded tissues extracted for use in polymerase chain reaction assays. Mod Pathol 1992;5:203-6.

18 Singer-Sam J, Tanguay RL, Riggs AD. Use of Chelex to improve the PCR signal from a small number of cells. Amplifications 1989;3:11.

19 Kawaski ES. Sample preparation from blood, cells, and other fluids. In: Innis MA, ed. PCR protocols: a guide to other fluids. In: Innis MA, ed. PCR protocols: a guide to
methods and applications. San Diego: Academic Press, methods and app

20 Gill $P$, Kimpton CP, Sullivan K. A rapid polymerase chain reaction method for identifying fixed specimens. Electrophoresis 1992;13:173-5.

21 Miller CW, Simon K, Aslo A, et al. p53 mutations in human lung tumors. Cancer Res 1992;52:1695-8.

22 Kwok S, Higuchi R. Avoiding false positives with PCR. Nature 1989;339:237-8.

23 Nuovo GJ, ed. In situ hybridization. In: $P C R$ in situ hybridization. New York: Raven Press, 1992:83-156.

24 Walsh PS, Metzger DA, Higuchi R. Chelex 100 as a medium for simple extraction of DNA for PCR-based medium for simple extraction of DNA for PCR-based typing f

25 Gelfand DH, White TJ. Thermostable DNA polymerases. In: Innis MA, ed. PCR protocols: a guide to methods and applications. San Diego: Academic Press, 1990: 129-41. 